\title{
The influence of a passion flower extract on free testosterone in healthy men: a two part investigation involving younger and older men
}

\author{
Richard J. Bloomer*, John J. MacDonnchadh, Trint A. Gunnels, and John Henry M. Schriefer \\ Cardiorespiratory/Metabolic Laboratory, The School of Health Studies, University of Memphis, Memphis, TN, USA
}

\begin{abstract}
Plant-based nutrients have been studied for their potential impact on testosterone production in men. We investigated the influence of a novel passion flower extract on free testosterone in healthy men. In part one of this study, 18 younger men (35.9 \pm 1.6 years) were assigned to consume placebo tablets or tablets containing a passion flower extract, in a random order, double-blind, cross-over design. The treatment period for each condition was 15 days, with a two-week washout period between conditions. Blood and saliva were collected both in the morning and the evening on days 1, 8, and 15-both before and one hour following ingestion of the assigned condition. In part two of this study, seven older men $(55.9 \pm 2.7$ years $)$ were assigned to consume the passion flower extract or placebo tablets in a random order, double-blind, cross-over design. The treatment period was the same as for part one and but only saliva was collected in the morning on days $1,3,8$, and 15 . All subjects completed a questionnaire on the morning of each test day to determine their subjective feelings associated with the condition treatment. Passion flower extract did not appear to influence free testosterone or subjective feelings in younger men. However, free salivary testosterone was increased an average of $13 \%$ in older men. In addition, an increase of $17 \%$ was noted from day 1 to day 15 for perceived energy level, while an increase of $9 \%$ was noted for libido when older men used the extract. A novel passion flower extract does not influence testosterone concentrations or subjective feelings in younger men but may have an influence on these outcomes in selected older men. It is possible that the treatment may be more effective when delivered to those with low baseline testosterone values.
\end{abstract}

\section{Introduction}

Vitamins, minerals, and certain botanicals are widely used to support human health [1]. Specific ingredients of interest have been reported to be associated with improved strength and muscle health, and are possibly associated with an increase in the hormone testosterone [2-4]. Although total circulating testosterone is correlated with improved strength, vitality, and libido, what appears to be the most important is the amount of free testosterone in circulation. This "free" testosterone is the biologically active form of testosterone and methods to enhance this fraction of testosterone are actively being pursued [5-13].

One such method of enhancing free testosterone is the ingestion of plant-based nutrients, often referred to as botanicals [14]. Indeed, prior reviews of literature indicate that certain botanicals may have favorable effects on circulating testosterone levels, with one such botanical being passion flower extract (passiflora incarnate $[15,16]$ ). However, to our knowledge, no human studies are available with regards to the use of passion flower extract for purposes of increasing testosterone levels. Therefore, the purpose of the present study was to determine the impact of a passion flower extract on blood free testosterone in healthy men. We used a two part investigation involving both younger and older men. In both cases, we utilized a randomized, placebo-controlled, cross-over design to determine the impact of short-term (15 day) supplementation with passion flower extract on free testosterone levels.

\section{Materials and methods}

\section{Subjects and screening}

Healthy men ( $\mathrm{n}=18$ for part $1 ; \mathrm{N}=7$ for part 2$)$ were enrolled in this study and completed all aspects of this work. Prior to participation, subjects completed a health history and physical activity questionnaire. Subjects did not have any history of cardiovascular disease, metabolic disease, or depression, nor did any subject smoke cigarettes. Subjects were not using cardiovascular or metabolic drugs of any kind. Subjects' height and weight were measured, as well as their body composition using dual energy x-ray absorptiometry. Resting heart rate and blood pressure were measured using palpation and cuff/stethoscope, respectively. Descriptive characteristics of subjects are presented in Table 1. The study protocol was approved by The University of Memphis Institutional Review Board for Human Subjects Research and subjects provided written informed consent prior to participating.

\section{Lab testing and conditions}

Following the initial screening procedures, subjects reported to the lab for testing both in the morning (6:00-9:00 am) and evening (6:009:00 $\mathrm{pm}$ ) for part 1 of the study. For part 2 , subjects simply reported to the lab in the morning. For morning visits, subjects reported following a 10-hour overnight fast, whereas for evening visits, subjects reported following a 4-hour fast. For each of the two conditions (active and placebo), testing was conducted over a 15 day period for each subject,

Correspondence to: Richard J. Bloomer, The School of Health Studies, 106 Roane Fieldhouse, The University of Memphis, Memphis, TN 38152, Tel: 901-6785638; Fax: 901-678-3591; E-mail: rbloomer@memphis.edu

Key words: passion flower, botanicals, testosterone, hormones, men

Received: February 01, 2015; Accepted: February 13, 2016; Published: February 16,2016 
Table 1. Characteristics of younger $(\mathrm{N}=18)$ and older $(\mathrm{N}=7)$ men

\begin{tabular}{|l|c|c|}
\hline Variable & $\begin{array}{c}\text { Men } \\
\text { N=18 }\end{array}$ & $\begin{array}{c}\text { Men } \\
\mathbf{N}=7\end{array}$ \\
\hline Age $(\mathrm{yrs})$ & $35.9 \pm 1.6$ & $55.9 \pm 2.7$ \\
\hline Height $(\mathrm{cm})$ & $179.8 \pm 1.4$ & $179.4 \pm 1.6$ \\
\hline Weight $(\mathrm{kg})$ & $88.2 \pm 1.9$ & $96.8 \pm 6.7$ \\
\hline BMI $\left(\mathrm{kg} \cdot \mathrm{m}^{-2}\right)$ & $27.3 \pm 0.5$ & $30.0 \pm 2.0$ \\
\hline Waist $(\mathrm{cm})$ & $94.8 \pm 1.4$ & $96.5 \pm 5.8$ \\
\hline Hip $(\mathrm{cm})$ & $105.4 \pm 1.1$ & $99.4 \pm 3.8$ \\
\hline Waist:Hip & $0.9 \pm 0.0$ & $1.0 \pm 0.0$ \\
\hline Body Fat $(\%)$ & $21.0 \pm 1.0$ & $24.4 \pm 1.8$ \\
\hline Heart Rate (bpm) & $65.4 \pm 2.4$ & $76.1 \pm 2.1$ \\
\hline Systolic Blood Pressure (mmHg) & $119.4 \pm 2.4$ & $128.0 \pm 2.8$ \\
\hline Diastolic Blood Pressure (mmHg) & $79.3 \pm 2.6$ & $77.9 \pm 2.1$ \\
\hline Years anaerobic exercise training & $6.9 \pm 2.2$ & $7.1 \pm 4.7$ \\
\hline Hours per week anaerobic exercise & $1.3 \pm 0.4$ & $0.5 \pm 0.3$ \\
\hline Years aerobic exercise training & $10.5 \pm 2.4$ & $16.6 \pm 5.5$ \\
\hline Hours per week aerobic exercise & $1.8 \pm 0.3$ & $2.1 \pm 0.5$ \\
\hline
\end{tabular}

Data are mean \pm SEM

with measures obtained on days 1, 8 and 15-involving both morning and evening visits for all three days (part 1); on days $1,3,8$, and 15 for part 2 . The time of day for morning and evening testing was matched for each subject on all test days.

Using a cross-over design, subjects were randomly assigned in double-blind manner to either the active botanical or placebo condition. A two week washout period separated conditions. All procedures, as described below, were identical for both conditions. The botanical agent and placebo were provided in fast dissolved tablets, to be placed under the tongue, and produced according to Good Manufacturing Practice (GMP). Each active tablet contained a dose of $62.5 \mathrm{mg}$ consisting of: passion flower extract; 7,8 benzoflavones and kudzu root lignan; 3,4 divanillyltetrahydrofuran in liposomes with absorption enhancer piperine liposome-all in a sublingual fast dissolve tablet. Each placebo tablet contained maltodextrin. Tablets were provided to subjects in blister packs and were similar in appearance. Subjects returned any unused tablets on the day of the final blood/saliva sample collection (as described below) and the remaining tablets were counted to determine compliance to intake.

A baseline fasting blood/saliva sample was obtained on the morning of day 1 of each condition (for part 1; only saliva samples were obtained in part 2). All subjects then consumed two tablets daily (1 tablet at approximately 6:00-7:00am; 1 tablet at approximately 6:007:00pm) starting on day 1, for fifteen days. Additional fasting blood/ saliva samples were obtained from subjects on subsequent days (8 and 15 for part $1 ; 3,8$, and 15 for part 2). Blood/saliva was collected in the morning/evening, both before and one hour after intake of the tablets. This was the same for both conditions (active and placebo). For part 2 only, duplicate saliva samples were obtained from each subject 30 minutes apart for each collection period; values were averaged to obtain the value used for data analysis.

\section{Test days}

Each lab visit took approximately 75 minutes. Subjects relaxed, read, used the computer, or watched TV during that time. Only water was allowed. An initial blood/saliva sample was collected from subjects. The assigned tablet was then ingested and an additional blood/ saliva sample was obtained one hour later. This concluded subjects' participation for that visit. The same procedures were followed for both morning and evening visits, for both active and placebo conditions, on all test days.

\section{Blood/saliva collection and biochemistry}

Blood samples (approximately $7 \mathrm{~mL}$ ) were collected from a forearm vein into a Vacutainer tube containing no additive, allowed to clot at room temperature for approximately 30 minutes, then centrifuged for 15 minutes at $4^{\circ} \mathrm{C}$ to obtain serum. Serum samples were stored at $-70^{\circ}$ until analyzed. Subjects provided saliva samples (approximately $1 \mathrm{~mL}$ ) by continuous, unstimulated passive drool into a special polypropylene collection tube (SaliCap: IBL International, Germany). A mirror was provided to subjects to assist in the filling of the tube and the time taken to fill the tube was approximately two minutes for most subjects. Subjects were instructed not to brush their teeth, to chew gum or mints, or to drink anything but water within one hour of providing the saliva sample. Five minutes before the saliva collection, subjects rinsed their mouth with water. Following the collection of saliva, samples were stored at $-70^{\circ}$ until analyzed.

Free testosterone was measured in serum and saliva within five weeks of collection. All samples were removed from the freezer, allowed to thaw at room temperature, and then mixed thoroughly. Saliva samples were then placed into a refrigerated centrifuge $\left(4^{\circ} \mathrm{C}\right)$ for 10 minutes at $2000 \mathrm{~g}$ in an attempt to produce a clean supernatant. This is the recommended duration and speed of centrifugation for saliva samples, as suggested by the ELISA manufacture (IBL International, Germany). For part 1, free testosterone concentrations were analyzed via ELISA procedures using $50 \mu \mathrm{L}$ of saliva (IBL International, Germany: catalog \# RE52631) and $25 \mu \mathrm{L}$ of serum (Cal Biotech, Spring Valley, CA: catalog \# FT178S). For part 2, free testosterone concentrations were analyzed via ELISA procedures using $25 \mu \mathrm{L}$ of saliva (Salimetrics, Carlsbad, CA: catalogue \# 1-2402). Certificates of quality control were provided for all ELISA kits. All samples were analyzed in duplicate on first thaw.

\section{Questionnaire}

Due to the potential influence of circulating testosterone on healthspecific parameters, a questionnaire was also completed by subjects on the morning of each test day. Using a scale of 1-5 (part 1) and 1-10 (part 2), with 1 representing the lowest rating and 5/10 representing the highest rating, subjects rated a number of variables pertaining to overall health with regards to how they felt over the past week (see Table 2 for the variables assessed).

\section{Dietary intake and physical activity}

Subjects were asked to maintain their usual dietary intake and physical activity program throughout the study period. They were also asked to refrain from alcohol consumption, strenuous physical activity, and sexual activity during the 48 hours prior to each test day. Finally, they were asked to obtain at least 7 hours of sleep during the night prior to each test day.

\section{Statistical analysis}

For part 1, testosterone data were analyzed using a 2 (condition) by 3 (test day) by 2 (morning/evening) by 2 (pre/post tablet ingestion) repeated measures analysis of variance (ANOVA). Subjective feelings data were analyzed using a 2 (condition) by 3 (test day) ANOVA. For part 2, testosterone data were analyzed using a 2 (condition) by 4 (test day) by 2 (pre/post tablet ingestion) repeated measures analysis of variance (ANOVA). Subjective feelings data were analyzed using 
Table 2. Perceived feelings of younger (A) and older (B) men assigned to botanical agent or placebo.

A

\begin{tabular}{|c|c|c|c|c|c|c|}
\hline Variable & $\begin{array}{c}\text { Botanical } \\
\text { Day } 1\end{array}$ & $\begin{array}{c}\text { Botanical } \\
\text { Day } 8\end{array}$ & $\begin{array}{c}\text { Botanical } \\
\text { Day } 15\end{array}$ & $\begin{array}{c}\text { Placebo } \\
\text { Day } 1\end{array}$ & $\begin{array}{c}\text { Placebo } \\
\text { Day } 8\end{array}$ & $\begin{array}{c}\text { Placebo } \\
\text { Day } 15\end{array}$ \\
\hline Alertness & $4.1 \pm 0.2$ & $4.0 \pm 0.2$ & $3.9 \pm 0.2$ & $3.9 \pm 0.2$ & $4.1 \pm 0.2$ & $3.9 \pm 0.1$ \\
\hline Energy Levels & $3.6 \pm 0.2$ & $4.0 \pm 0.2$ & $3.8 \pm 0$ & $3.8 \pm 0.2$ & $4.0 \pm 0.2$ & $4.1 \pm 0.2$ \\
\hline Vitality & $3.8 \pm 0.2$ & $3.9 \pm 0.2$ & $3.9 \pm 0.2$ & $3.9 \pm 0.2$ & $3.8 \pm 0.2$ & $3.9 \pm 0.2$ \\
\hline Libido & $3.9 \pm 0.2$ & $4.2 \pm 0.2$ & $4.1 \pm 0.3$ & $3.7 \pm 0.2$ & $3.9 \pm 0.2$ & $4.0 \pm 0.2$ \\
\hline Workout Effectiveness & $3.6 \pm 0.2$ & $3.7 \pm 0.2$ & $3.8 \pm 0.3$ & $3.6 \pm 0.2$ & $4.1 \pm 0.3$ & $3.9 \pm 0.2$ \\
\hline Muscle Strength & $3.7 \pm 0.2$ & $3.8 \pm 0.2$ & $3.9 \pm 0.2$ & $3.7 \pm 0.2$ & $3.8 \pm 0.2$ & $3.9 \pm 0.2$ \\
\hline Muscle Endurance & $3.4 \pm 0.2$ & $3.8 \pm 0.1$ & $3.8 \pm 0.2$ & $3.5 \pm 0.2$ & $3.8 \pm 0.2$ & $3.9 \pm 0.2$ \\
\hline Sleep Quality & $3.3 \pm 0.3$ & $3.4 \pm 0.2$ & $3.4 \pm 0.2$ & $3.1 \pm 0.2$ & $3.5 \pm 0.2$ & $3.9 \pm 0.2$ \\
\hline Mental Outlook and Mood & $3.9 \pm 0.1$ & $3.9 \pm 0.2$ & $3.9 \pm 0.2$ & $3.7 \pm 0.2$ & $4.0 \pm 0.2$ & $3.9 \pm 0.2$ \\
\hline Physical Appearance & $3.7 \pm 0.2$ & $3.9 \pm 0.1$ & $3.8 \pm 0.2$ & $3.7 \pm .02$ & $3.7 \pm 0.2$ & $3.8 \pm 0.2$ \\
\hline
\end{tabular}

B

\begin{tabular}{|l|c|c|c|c|c|c|c|c|}
\hline Variable & $\begin{array}{c}\text { Botanical } \\
\text { Day 1 }\end{array}$ & $\begin{array}{c}\text { Botanical } \\
\text { Day 3 }\end{array}$ & $\begin{array}{c}\text { Botanical } \\
\text { Day 8 }\end{array}$ & $\begin{array}{c}\text { Botanical } \\
\text { Day 15 }\end{array}$ & $\begin{array}{c}\text { Placebo } \\
\text { Day 1 }\end{array}$ & $\begin{array}{c}\text { Placebo } \\
\text { Day 3 }\end{array}$ & $\begin{array}{c}\text { Placebo } \\
\text { Day 8 }\end{array}$ & $\begin{array}{c}\text { Placebo } \\
\text { Day 15 }\end{array}$ \\
\hline Alertness & $7.4 \pm 0.9$ & $7.3 \pm 0.5$ & $7.4 \pm 0.4$ & $7.4 \pm 0.4$ & $7.7 \pm 0.7$ & $7.6 \pm 0.8$ & $7.4 \pm 1.0$ & $7.6 \pm 0.6$ \\
\hline Energy Levels & $6.3 \pm 0.8$ & $7.3 \pm 0.9$ & $6.7 \pm 0.8$ & $7.4 \pm 0.6$ & $7.3 \pm 0.5$ & $6.7 \pm 1.0$ & $7.0 \pm 0.9$ & $7.3 \pm 0.8$ \\
\hline Vitality & $6.9 \pm 0.9$ & $6.9 \pm 0.9$ & $7.6 \pm 0.8$ & $6.6 \pm 0.8$ & $7.1 \pm 0.9$ & $6.4 \pm 0.9$ & $7.3 \pm 0.5$ & $7.0 \pm 0.9$ \\
\hline Libido & $6.7 \pm 1.0$ & $6.6 \pm 1.0$ & $7.1 \pm 0.8$ & $7.3 \pm 0.7$ & $6.1 \pm 1.1$ & $6.3 \pm 0.8$ & $6.3 \pm 1.1$ \\
\hline Muscle Strength & $6.6 \pm 0.6$ & $6.7 \pm 0.5$ & $6.7 \pm 0.5$ & $6.1 \pm 0.8$ & $6.0 \pm 0.8$ & $6.1 \pm 0.8$ & $6.9 \pm 0.6$ & $6.9 \pm 0.9$ \\
\hline Muscle Endurance & $6.1 \pm 0.8$ & $6.0 \pm 0.7$ & $6.9 \pm 0.4$ & $6.3 \pm 0.8$ & $6.1 \pm 0.9$ & $6.1 \pm 0.8$ & $6.3 \pm 0.8$ & $6.3 \pm 0.8$ \\
\hline Sleep Quality & $6.3 \pm 0.6$ & $7.3 \pm 0.4$ & $7.1 \pm 0.5$ & $6.6 \pm 0.8$ & $6.4 \pm 0.9$ & $7.3 \pm 0.7$ & $7.6 \pm 0.8$ & $7.6 \pm 0.7$ \\
\hline Mental Outlook \& Mood & $6.9 \pm 0.8$ & $7.1 \pm 0.7$ & $7.3 \pm 0.6$ & $7.7 \pm 0.7$ & $7.4 \pm 1.0$ & $7.7 \pm 0.9$ & $7.4 \pm 0.6$ & $8.0 \pm 0.6$ \\
\hline Physical Appearance & $6.0 \pm 0.8$ & $6.0 \pm 0.8$ & $6.0 \pm 0.9$ & $6.3 \pm 0.8$ & $6.3 \pm 1.3$ & $6.0 \pm 0.9$ & $6.0 \pm 1.0$ & $6.6 \pm 1.0$ \\
\hline
\end{tabular}

Data are mean \pm SEM.

No statistically significant differences noted $(\mathrm{p}>0.05)$.

a 2 (condition) by 4 (test day) ANOVA. All analyses were performed using JMP statistical software (version 4.0.3, SAS Institute, Cary, NC). Statistical significance was set at $\mathrm{P} \leq 0.05$. The data are presented as mean \pm SEM.

\section{Results}

All subjects successfully completed the protocol. No adverse outcomes were noted with treatment and all subjects tolerated the treatment well with the following exception: one older adult reported that he experienced leg cramping upon going to bed at night. The subject reported that cramps of this nature are a recurring symptom he has experienced but he believed that the episodes were occurring more frequently than normal. This was reported to our IRB and to the study sponsor.

Subject characteristics are presented in Table 1. For part 1, with the exception of lower testosterone values in both blood $(\mathrm{p}<0.0001)$ and saliva ( $\mathrm{p}=0.0002)$ during the evening hours compared to morning hours, no statistically significant differences were noted between conditions or across time for either testosterone or subjective feelings ( $p>0.05)$. Data for subjective feelings are presented in Table 2A. Data for blood and saliva testosterone are presented in Table 3.

For part 2, no changes of statistical significance were noted ( $p>0.05)$. However, when the percent change in saliva testosterone from day 1 was calculated, an increase of $13 \%$ was noted at day 3 when men used the extract, compared to an increase of $2 \%$ when men used the placebo $(\mathrm{p}=0.29)$. Of the seven men tested, saliva testosterone was increased across time (the average increase on day 3,8, and 15) from day 1 in four of the men (range: $4 \%$ to $20 \%$ ). Within this group of responders, a peak response of $28 \%$ was noted in free testosterone in one subject on day 8 . However, when considering only these four men, significant differences between the extract and the placebo could not be detected ( $p>0.05$; Table 4). Considering all seven men, an increase of $17 \%$ was noted from day 1 to day 15 for perceived energy level, while an increase of $9 \%$ was noted for libido when men used the extract (Table 2B).

\section{Discussion}

To our knowledge, the present study was the first to evaluate the impact of a passion flower extract on free testosterone in healthy men. Results indicated that no statistically significant differences were noted between placebo or passion flower extract for either testosterone or subjective feelings. That said, selected older men appeared to benefit from use of the extract and these findings merit further investigation.

Specifically, a peak mean change in saliva testosterone of $13 \%$ was noted when men used the extract. Of the seven older men tested, saliva testosterone was increased across time (the average increase on day 3,8 , and 15 ) from day 1 in four of the men (range: $4 \%$ to $20 \%$ ). A larger sample of men, ideally with similar basal testosterone values (in an attempt to reduce variability), is needed to extend these findings. Aside from the increase in salivary testosterone, perceived energy level was noted to increase by $17 \%$, while libido also increased $9 \%$ when men used the extract. As with many dietary supplements, some individuals appear "responders" to treatment while some are not. The variability in response between subjects, the relatively small sample size, and the potential for lack of control of certain extrinsic variables (e.g., nightly sleep) that may influence testosterone concentration in men may have collectively impaired our ability to detect changes of statistical significance. Any potential follow-up study should include a larger sample of men, possibly inclusive of classic symptoms of low testosterone (e.g., lethargy, depression, loss of libido), in an attempt to 
Table 3. Serum and saliva free testosterone values $\left(\mathrm{pg} \cdot \mathrm{mL}^{-1}\right)$ of younger men receiving botanical agent or placebo.

\begin{tabular}{|c|c|c|c|c|c|}
\hline Condition & Day & $\mathbf{a m} / \mathbf{p m} \dagger$ & Pre/Post* & Serum & Saliva \\
\hline Botanical & 1 & am & Pre & $5.15 \pm 0.33$ & $388.84 \pm 85.55$ \\
\hline Botanical & 1 & am & Post & $5.08 \pm 0.29$ & $457.77 \pm 85.49$ \\
\hline Botanical & 1 & $\mathrm{pm}$ & Pre & $4.44 \pm 0.27$ & $270.18 \pm 66.57$ \\
\hline Botanical & 1 & $\mathrm{pm}$ & Post & $4.36 \pm 0.22$ & $342.38 \pm 68.57$ \\
\hline Botanical & 8 & am & Pre & $5.04 \pm 0.26$ & $397.08 \pm 87.05$ \\
\hline Botanical & 8 & am & Post & $5.24 \pm 0.35$ & $443.97 \pm 69.83$ \\
\hline Botanical & 8 & $\mathrm{pm}$ & Pre & $4.39 \pm 0.23$ & $249.43 \pm 58.52$ \\
\hline Botanical & 8 & $\mathrm{pm}$ & Post & $4.20 \pm 0.26$ & $301.09 \pm 61.77$ \\
\hline Botanical & 15 & am & Pre & $5.01 \pm 0.31$ & $369.48 \pm 68.64$ \\
\hline Botanical & 15 & am & Post & $5.25 \pm 0.33$ & $377.59 \pm 66.44$ \\
\hline Botanical & 15 & $\mathrm{pm}$ & Pre & $4.39 \pm 0.26$ & $314.88 \pm 57.09$ \\
\hline Botanical & 15 & $\mathrm{pm}$ & Post & $4.45 \pm 0.24$ & $313.83 \pm 52.17$ \\
\hline Placebo & 1 & $\mathrm{am}$ & Pre & $5.09 \pm 0.32$ & $427.84 \pm 67.86$ \\
\hline Placebo & 1 & am & Post & $5.19 \pm 0.33$ & $443.29 \pm 72.59$ \\
\hline Placebo & 1 & $\mathrm{pm}$ & Pre & $4.35 \pm 0.24$ & $300.05 \pm 61.52$ \\
\hline Placebo & 1 & $\mathrm{pm}$ & Post & $4.24 \pm 0.20$ & $320.18 \pm 67.45$ \\
\hline Placebo & 8 & am & Pre & $4.72 \pm 0.29$ & $307.54 \pm 48.45$ \\
\hline Placebo & 8 & am & Post & $4.90 \pm 0.28$ & $378.41 \pm 59.57$ \\
\hline Placebo & 8 & $\mathrm{pm}$ & Pre & $4.11 \pm 0.25$ & $236.91 \pm 41.88$ \\
\hline Placebo & 8 & $\mathrm{pm}$ & Post & $4.22 \pm 0.25$ & $256.72 \pm 39.37$ \\
\hline Placebo & 15 & am & Pre & $4.75 \pm 0.32$ & $396.46 \pm 60.66$ \\
\hline Placebo & 15 & am & Post & $4.90 \pm 0.31$ & $408.80 \pm 57.59$ \\
\hline Placebo & 15 & $\mathrm{pm}$ & Pre & $4.15 \pm 0.19$ & $290.83 \pm 51.61$ \\
\hline Placebo & 15 & $\mathrm{pm}$ & Post & $4.14 \pm 0.18$ & $330.32 \pm 47.24$ \\
\hline
\end{tabular}

*Pre: prior to receiving condition; Post: $1 \mathrm{hr}$ after receiving condition

Data are mean \pm SEM. $\uparrow$ Values greater for am versus $\mathrm{pm}$ for serum $(\mathrm{p}<0.0001)$ and saliva $(\mathrm{p}=0.0002)$.

No other statistically significant differences noted $(\mathrm{p}>0.05)$.

Table 4. Saliva free testosterone values $\left(\mathrm{pg} \cdot \mathrm{mL}^{-1}\right)$ of older men receiving botanical agent or placebo.

\begin{tabular}{|l|c|c|c|}
\hline Condition & Day & Pre/Post* & Saliva \\
\hline Botanical & 1 & Pre & $107.2 \pm 13.1$ \\
\hline Botanical & 1 & Post & $122.7 \pm 22.2$ \\
\hline Botanical & 3 & Pre & $122.7 \pm 16.7$ \\
\hline Botanical & 3 & Post & $92.7 \pm 11.7$ \\
\hline Botanical & 8 & Pre & $108.2 \pm 9.4$ \\
\hline Botanical & 8 & Post & $123.7 \pm 13.7$ \\
\hline Botanical & 15 & Pre & $110.3 \pm 15.2$ \\
\hline Botanical & 15 & Post & $93.7 \pm 12.2$ \\
\hline Placebo & 1 & Pre & $98.0 \pm 14.5$ \\
\hline Placebo & 1 & Post & $98.6 \pm 17.4$ \\
\hline Placebo & 3 & Pre & $111.3 \pm 22.1$ \\
\hline Placebo & 3 & Post & $88.7 \pm 17.2$ \\
\hline Placebo & 8 & Pre & $103.7 \pm 16.9$ \\
\hline Placebo & 8 & Post & $89.9 \pm 10.7$ \\
\hline Placebo & 15 & Pre & $97.1 \pm 11.1$ \\
\hline Placebo & 15 & Post & $98.3 \pm 18.3$ \\
\hline
\end{tabular}

*Pre: prior to receiving condition; Post: $1 \mathrm{hr}$ after receiving condition

Data are mean \pm SEM. No statistically significant differences noted ( $p>0.05)$.

determine if the passion flower extract can provide a meaningful boost to testosterone. Moreover, we may pre-screen individuals to determine who might be classified as "responders" to treatment. In addition, as use of testosterone therapy is gaining popularity among middleaged and pre-menopausal women who experience similar symptoms as indicated above, an investigation involving women may be of interest. Currently, few if any dietary supplements are available which are specifically targeted to women who have the goal of increasing testosterone for purposes of improving general health and well-being.

Passion flower extract is thought to elevate circulating testosterone by the inhibition of aromatase activity, a member of cytochrome P-450 enzyme family, which may prevent the conversion of testosterone to its metabolites. The subsequent result would be to maintain testosterone levels in the gonadal tissue. In the only published study that we are aware of pertaining to passion flower extract and testosterone levels, Dhawan and Sharma found that testosterone was increased when albino Wistar rats supplemented with passiflora extracts suspended in simple syrup [8]. Based on these limited findings, additional research is necessary to ascertain the impact of passion flower extract on circulating testosterone in humans.

As expected, testosterone values were lower during the evening hours as compared to the morning hours (Table 3) (10). Beyond this difference, there was no increase in testosterone in either saliva or blood samples when individuals ingested the botanical extract acutely or chronically (Table 3). We have several potential explanations for our lack of noted effect. First, it is possible that due to the relatively young age of subjects ( $35.9 \pm 1.6$ years), baseline testosterone levels were too high to be favorably impacted by the botanical treatment. This may be the reason why we noted some benefit in the older adults treated with the extract.

Second, it is possible that individuals did not appropriately ingest the assigned treatment. That is, they were instructed how to use the assigned treatment by placing the tablet under the tongue and waiting for it to dissolve into the mucosa. Our pilot testing indicated that a time frame of approximately 15 minutes was required for the tablet to completely dissolve. Some subjects may have become impatient and simply swallowed the tablet. If this was the case, the active ingredient would have entered the gastrointestinal tract rather than the desired oral mucosal membranes; hence, the end result of elevated testosterone may not have been realized.

Third, it is possible that subjects failed to follow all instructions for each laboratory visit, including those involving food intake, the avoidance of strenuous exercise, and the obtainment of adequate sleep during the night before each test day. As all of these variables may have influenced outcomes, failure to abide by our suggested guidelines could have confounded the results.

Forth, due to differences in assay format between the two saliva ELISA kits, it is possible that differing results would have been obtained for younger men if the Salimetrics assay kit were used to analyze those samples. The choice to use the Salimetrics kit for the older men samples was made after completing the younger adult study and performing a comparison between the IBL and Salimetrics kits. The overall performance of the Salimetrics kit appeared better and hence, the decision was made to use this kit to analyze the older men samples. As can be seen by comparing saliva testosterone values in Tables 3 and 4, significant differences are apparent, with values 3-4 times higher with the IBL kit compared with the Salimetrics kit. Of course, some of the discrepancy may be due to actual differences in testosterone concentration within the sample. Nevertheless, this may be considered by those planning to analyze testosterone in human saliva samples. 
In a small pilot experiment involving five men (four under the age of 30; one age 41) and one woman (age 36), ingesting either a double dosage of the passion flower extract for one week or the standard dosage over a period of several weeks, an increase in saliva testosterone was noted in selected individuals. Of note, one man (age 41) and the woman experienced an approximate $30 \%$ increase in saliva testosterone following the initial three days of treatment. Moreover, the woman experienced a dramatic improvement in overall mood and energy levels over the course of several weeks of treatment with the botanical extract. No increase was noted in blood testosterone.

\section{Conclusions}

A novel passion flower extract does not result in any significant increase in testosterone in younger men but may have an impact in certain older men. It is possible that the treatment may be more effective when provided to those who have a low baseline testosterone value. If future studies are conducted in such individuals (e.g. older men, women), associated variables (e.g. mood, energy levels, muscle strength, muscle mass) should be considered for inclusion within the research design.

\section{Acknowledgments}

Funding for this work was provided in part by Smartek, LLC and the University of Memphis.

\section{Competing interests}

Financial support for this work was provided in part by Smartek, LLC. None of the authors have a financial interest in this company. RJB has received research funding or acted as consultant to other nutraceutical and dietary supplement companies. All other authors declare no competing interests.

\section{Authors' contributions}

RJB was responsible for the study design, biochemical work, statistical analyses, and manuscript preparation. JJM, TAG and JMS were responsible for subject recruitment, data collection, blood/saliva collection and processing, data entry, and assistance with manuscript preparation. All authors read and approved of the final manuscript.

\section{References}

1. Bailey RL, Gahche JJ, Miller PE, Thomas PR, Dwyer JT (2013) Why US adults use dietary supplements. JAMA Intern Med 173: 355-361. [Crossref]

2. Dean W (2012) Anti-Aging and Life Extension Chrysin: Is It An Effective Aromatase Inhibitor?
3. Lambert JD, Hong J, Kim DH, Mishin VM, Yang CS (2004) Piperine enhances the bioavailability of the tea polyphenol (-)-epigallocatechin-3-gallate in mice. J Nutr 134: 1948-1952. [Crossref]

4. Brown GA, Vukovich MD, Martini ER, Kohut ML, Franke WD, et al. (2001) Endocrine and lipid responses to chronic androstenediol-herbal supplementation in 30 to 58 year old men. J Am Coll Nutr 20: 520-528. [Crossref]

5. Arazi H, Damirchi A, Faraji H, Rahimi R (2012) Hormonal responses to acute and chronic resistance exercise in middle-age versus young men. Sport Sciences for Health 8: 59-65.

6. Brown GA, Vukovich MD, Reifenrath TA, Uhl NL, Parsons KA, et al. (2000) Effects of Anabolic Precursors on Serum Testosterone Concentrations and Adaptations to Resistance Training in Young Men. Int J Sport Nutr Exerc Metah 10: 340. [Crossref]

7. Bushey, B, Taylor, LW, Wilborn, CW, Poole, C, Foster, CA, Campbell, B, Kreider, RB, and Willoughby, DS. Fenugreek extract supplementation has no effect on the hormonal profile of resitance-trained males. In: Proceedings of International Journal of Exercise Science: Conference Proceedings. Anonymous, 2009. pp. 13. [Crossref]

8. Eisenegger C, von Eckardstein A, Fehr E, von Eckardstein S (2013) Pharmacokinetics of testosterone and estradiol gel preparations in healthy young men. Psychoneuroendocrinology 38: 171-178. [Crossref]

9. Khera M, Bhattacharya RK, Blick G, Kushner H, Nguyen D, et al. (2011) Improved Sexual Function with Testosterone Replacement Therapy in Hypogonadal Men: RealWorld Data from the Testim Registry in the United States (TRiUS). J Sex Med 8: 32043213. [Crossref]

10. Markowitz JS, DeVane CL, Lewis JG, Chavin KD, Wang JS, et al. (2005) Effect of Ginkgo biloba extract on plasma steroid concentrations in healthy volunteers: A pilot study. Pharmacotherapy 25: 1337-1340. [Crossref]

11. Topo E, Soricelli A, D'Aniello A, Ronsini S, D'Aniello G (2009) The role and molecular mechanism of D-aspartic acid in the release and synthesis of LH and testosterone in humans and rats. Reprod Biol Endocrinol 7: 120. [Crossref]

12. Willoughby, DS, Leutholtz, B (2013) D-Aspartic acid supplementation combined with 28 days of heavy resistance training has no effect on body composition, muscle strength, and serum hormones associated with the hypothalamo-pituitary-gonadal axis in resistance-trained men. Nutr Res 33: 803-810 [Crossref]

13. Willoughby, DS, Spillane, M, and Schwarz, N (2013) Heavy Resistance Training and Supplementation with the Alleged Testosterone Booster NMDA Has No Effect on Body Composition, Muscle Performance, and Serum Hormones Associated with the Hypothalamo-Pituitary-Gonadal Axis in Resistance-Trained Males. J Sports Sci Med 12: 192-199. [Crossref]

14. Bloomer R, Gunnels T (2014) Increasing circulating testosterone: Impact of herbal dietary supplements. J Plant Biochem Physiol: Open Access.

15. Dhawan, K, Sharma A (2002) Prevention of chronic alcohol and nicotine-induced azospermia, sterility and decreased libido, by a novel tri-substituted benzoflavone moiety from $<\mathrm{i}>$ Passiflora incarnata Linneaus in healthy male rats. Life Sci 71: 30593069. [Crossref]

16. Patel S, Mohamed Saleem T, Ravi V, Shrestha B, Verma N, et al. (2009) Passiflora incarnata Linn: A phytopharmacological review. Int J Green Pharm 3: 277.

Copyright: $₫ 2016$ Bloomer RJ. This is an open-access article distributed under the terms of the Creative Commons Attribution License, which permits unrestricted use, distribution, and reproduction in any medium, provided the original author and source are credited. 